\title{
Impact Analysis on Water Quality of the Second Songhua River Based on Mathematical Model
}

\author{
Sun Shao-Chen, Zhou Zu-Hao, Xiao Wei-Hua, and Wang Hao
}

\begin{abstract}
Water quality of the second Songhua River is affected by both tributary pollution loads and upper boundary. A set of hydrodynamics and water quality coupling model of the second Songhua River was developed. Based on the model, the pollution contribution ratios of tributaries pollution loads and boundaries were ascertained. The impacts of the change of water qualities of upper boundary and tributary were analyzed, and the farthermost water quality improvement of second Songhua River when upper boundary being better and tributary meeting Class III of National Surface Water Quality Standard was predicted. The results indicated: 1)if the tributary (Yinma river )meets Class III of National Surface Water Quality Standard, the water quality of WUJIA water quality monitoring station in Songhua river improving will be bigger from Jun through Aug, Ammonia and Nitrogen Index was significantly improved, but to upper boundary, this kind of impact is bigger. 2) Both reducing the tributaries pollution loads and improving upper boundaries are necessary for improving water quality in the second Songhua River.
\end{abstract}

Index Terms-Mathematical model, the second Songhua River, tributary, water qualities .

\section{INTRODUCTION}

The second Songhua River takes an important place in the economic development in Jilin province. However, in recent years many problems have been brought about by irrational reclamation of wasteland, irrational diversion from the source streams and large volume of untreated sewage drained into the river.

From Table I, we can see the water quality deterioration at the downstream of the Long tan Bridge in city of Jilin, especially at the downstream of the Songhua river (VI) monitoring station, the water is seriously polluted and has a trend of becoming more and more seriously. The major pollution indexs was $\mathrm{BOD}_{5}, \mathrm{COD}$ and $\mathrm{NH}_{3}-\mathrm{N}$.

In 2005, the tributaries in inland river basins including Huifa river, Yinma river and Yitong river have bad water qualities (poor V) [1]. The major pollution indexs was $\mathrm{BOD}_{5}$, COD and $\mathrm{NH}_{3}-\mathrm{N}$.

Manuscript received May 5, 2013; revised July 10, 2013. This study was supported by the National Natural Science Foundation of China (51179203), National Science and Technology Major Project of Water Pollution Control and Prevention (2012ZX07201006, 2012ZX07207-007), the Foundation for Innovative Research Groups of the National Natural Science Foundation of China (51021006)

Sun Shao-Chen is with Environmental Management College of China, Qinhuangdao, China (e-mail: sunshaochen@126.com).

Zhou Zu-Hao, Xiao Wei-Hua, and Wang Hao are with China Institute of Water Resources and Hydropower Research, Beijing, China (e-mail: zhzh@iwhr.com; xwsen998@163.com;).
TABLE II: WATER QUALITY STATE OF THE SECOND SONGHUA RIVER

\begin{tabular}{|l|l|l|l|l|l|l|l|}
\hline $\begin{array}{l}\text { Monitoring } \\
\text { sections }\end{array}$ & 2000 & 2001 & 2002 & 2003 & 2004 & 2005 & $\begin{array}{l}\text { major } \\
\text { pollution } \\
\text { index }\end{array}$ \\
\hline $\begin{array}{l}\text { White mountain } \\
\text { bridge }\end{array}$ & III & IV & III & III & III & IV & $\mathrm{COD}_{\mathrm{Mn}}$ \\
\hline Linjiang bridge & IV & IV & IV & III & III & IV & $\mathrm{COD}_{\mathrm{Mn}}$ \\
\hline Fengman & III & III & III & III & III & III & \\
\hline Longtan bridge & III & III & III & III & III & III & \\
\hline Nine stage & V & V & V & IV & IV & IV & $\mathrm{NH}_{3}-\mathrm{N}$ \\
\hline Shaokou & V & IV & III & IV & IV & IV & $\mathrm{NH}_{3}-\mathrm{N}$ \\
\hline Baiqi & IV & IV & III & IV & III & III & $\mathrm{COD}_{\mathrm{Mn}}$ \\
\hline $\begin{array}{l}\text { Songhua } \\
\text { river(six) }\end{array}$ & IV & III & III & $>$ V & V & $>$ V & $\mathrm{COD}_{\mathrm{Mn}}$ \\
\hline Zhenjiangkou & IV & IV & III & $>$ V & $>$ V & V & $\mathrm{NH}_{3}-\mathrm{N}$ \\
\hline $\begin{array}{l}\text { Stock farm } \\
\text { station }\end{array}$ & IV & IV & III & III & III & III & $\mathrm{COD}_{\mathrm{Mn}}$ \\
\hline Hogwash crock & IV & IV & IV & III & III & III & $\mathrm{COD}_{\mathrm{Mn}}$ \\
\hline
\end{tabular}

From Table II, Monitoring results indicated that the Dehui station which is a part of Yinma River and Kaoshan station which is a part of Yitong River have worse water quality, which indicates this area has received lots of pollution sources. The water quality of main stream will be influenced when the water of tributaries flow into.

TABLE II: THE WATER QUALITY OF YINMA RIVER AND YITONG RIVER IN 2007

\begin{tabular}{|l|l|l|l|l|l|}
\hline tributaries & water quality station & $\mathrm{NH}_{3}-\mathrm{N}$ & $\mathrm{COD}_{\mathrm{cr}}$ & $\mathrm{COD}_{\mathrm{mn}}$ & $\mathrm{BOD}_{5}$ \\
\hline Yinma river & Dehui & $\mathrm{IV}$ & $\mathrm{V}$ & $\mathrm{IV}$ & $\mathrm{V}$ \\
\hline Yitong river & Kaoshan & $\mathrm{V}$ & $>\mathrm{V}$ & $>\mathrm{V}$ & $>\mathrm{V}$ \\
\hline
\end{tabular}

The water quality of the second Songhua River receives much concern all the time [2-7]. The water quality is affected by upriver, local pollution source and the tributaries. The second Songhua River is broad and has a well-developed river system, and each water area in the river basin has different environmental conditions, hydrology conditions and chemical compositions, also the type and quantity of pollution that has been received are different, the pollution conditions are different from parts of the main river to the tributaries. It is necessary to analyze the influence of water quality from upriver and tributaries. This paper studies the influence factors of the second Songhua river pollution using the mathematical model.

Water quality question in water bodies have been extensively studied using various numerical models in the past decades. The implicit finite-difference method has been widely used for the solution of one-dimensional unsteady open-channel flow problems [8-12], Mossman et al. [13] set up one-dimensional unsteady contaminant transport model 
for rivers networks using a split-operator format for solving the advective-dispersive-reactive equation. Vieira [14] developed water quality module CCHE1D-WQ to simulate transport in streams for continuous, unsteady flow by a control volume method.

The aim of this work is to establish a hydrodynamic and water quality model for the second Songhua river networks. This article uses a nonlinear fully-implicit finite difference scheme to discretize the Saint-Venant equations and applies the method of three-step solution for river networks and channel-junction-channel to simulate the river networks.

The simulated water quality constituents concentration, water level and discharge are in good agreement with field observations. The influence of the main river from upriver and tributaries are compared, and the farthermost water quality improvement of the second Songhua river when upper boundary being better and tributary meeting class III of National Surface Water Quality Standard is predicted. Decision-making judgments for govern project of Songhua river are provided.

\section{MATHEMATIC MODEL}

\section{A. Hydrodynamic Model}

1-D Saint-Venant equation set is used to simulate the water flow movement of river network written as follows: Continuity equation:

$$
\frac{\partial Q}{\partial s}+B \frac{\partial z}{\partial t}=q_{L}
$$

Momentum equation:

$$
\frac{\partial Q}{\partial t}+\frac{\partial}{\partial s}\left(\frac{Q^{2}}{A}\right)+g A \frac{\partial Z}{\partial s}+g \frac{Q|Q|}{V^{2} A R}=0
$$

in which $s$ denotes the distance in $x$ direction, $t$ is time variable, $Q$ and $Z$ are the section average discharge and water level, $g$ is the acceleration of gravity, $B$ is the total water surface width, $q_{L}$ is the lateral inflow, $R$ is the hydraulic radius, $V$ is the Chezy coefficient, $A$ is the lateral cross section area.

The governing equations can be discretized with implicit finite-difference method, which has been described concretely in previous studies.

\section{B. Water Quality Model}

One-dimensional water quality model written as follows:

$$
\frac{\partial C}{\partial t}+u \frac{\partial C}{\partial x}=E \frac{\partial^{2} C}{\partial x^{2}}-k c
$$

where $C$ is the concentration of pollutant constituents, $u$ is the velocity of flow, $E$ is the dispersion coefficient (Fisher Semi-empirical Formula), $x$ is the longitudinal coordinates, $t$ is the time, $k$ is the mass decay rate.

The water quality equation is descretized by the implicit scheme:

$$
D_{i} C_{i-1}^{j+1}+B_{i} C_{i}^{j+1}+U_{i} C_{i+1}^{j+1}=F_{i}
$$

where $D_{i}, B_{i}, U_{i}$ and $F_{i}$ are the coefficients of Eq. solving matrix with pursuing method.

\section{CALIBRATION OF HYDRODYNAMIC AND WATER QUALITY MODEL}

\section{A. Calibration of Hydrodynamic Model}

Fig. 1 shows the structure of study area, where the water quality is poor, and in which the Songhua River (VI) hydrometric station is sited upstream boundary, while the Fuyu (III) hydrometric station is settled downstream boundary. The space step is $500 \mathrm{~m}$ and the time step is $10 \mathrm{~min}$ in the simulation. The upstream boundary is given discharge curve and the downstream boundary is preset stage hydrograph in the process of hydrodynamic calculation. Hydrodynamic model is calibrated and verified by measured data of water level and flow from April to October in 2006 and 2007. The roughness coefficient, which is the basic calibration parameter, is $0.025 \sim 0.033$ through calibrating in this area. Some calibration results are shown as Fig. 2 and Fig. 3. The water level and flow of the calculated values and measured values are quite consistent from the calibration verification results. Based on the analysis, we can conclude that the calibrated model could meet the needs of the engineering analysis accuracy.

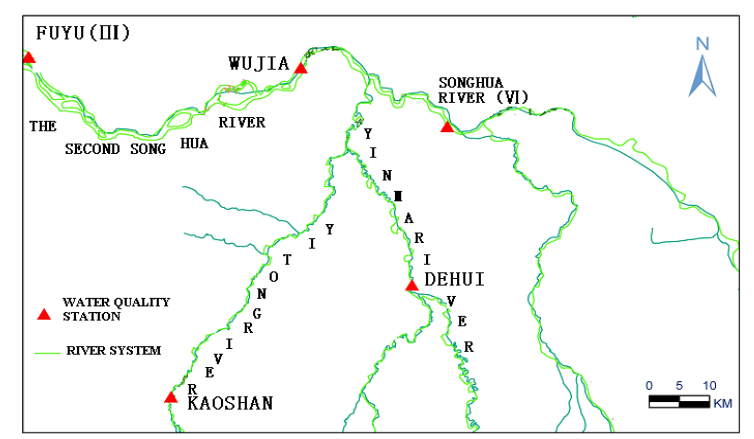

Fig. 1. Structure of study area

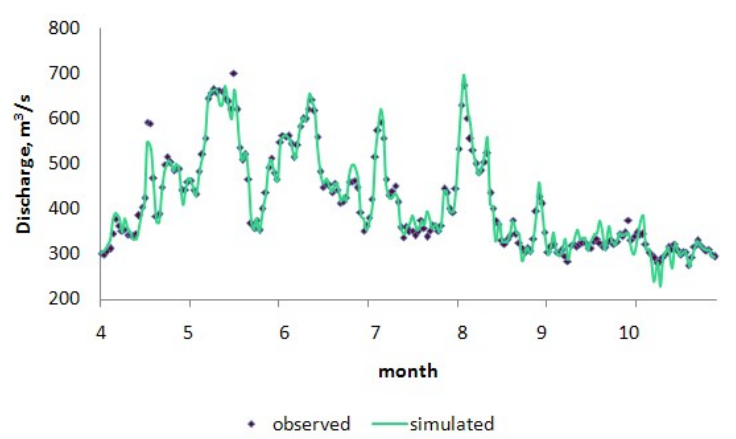

Fig. 2. Comparison of discharge at Fuyu (III) station

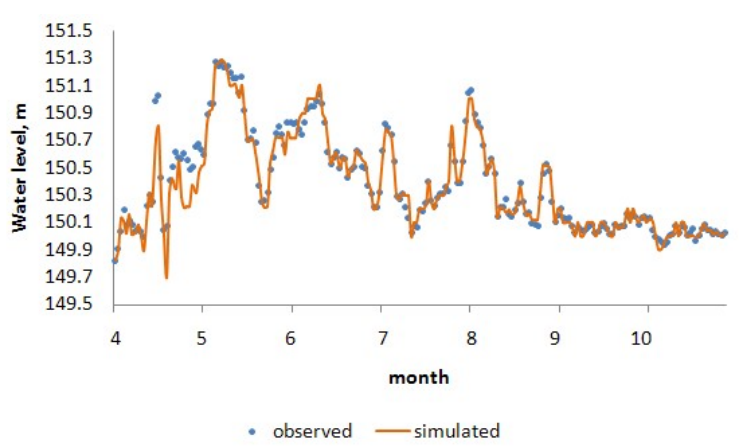

Fig. 3. Comparison of water level at Songhua river (VI) station 


\section{B. Calibration of Water Quality Model}

The time-histories on consistence of ammonia nitrogen and COD variables are given by the water quality boundary. The COD concentration is $10 \sim 15 \mathrm{mg} / \mathrm{l}$ and the ammonia nitrogen concentration is $0.5 \sim 0.7 \mathrm{mg} / 1$ on the serial sections between the main stream way upstream and downstream at the beginning. Meanwhile the COD concentration is $30 \sim$ $50 \mathrm{mg} / \mathrm{l}$ and the ammonia nitrogen concentration is $3 \sim$ $35 \mathrm{mg} / \mathrm{l}$ on the section of the tributary. The attenuation coefficient of COD is $0.15 \sim 0.33$ per day and the ammonia nitrogen is $0.08 \sim 0.25$ per day.

The verified results of water quality model which are calibrated with the synchronism hydrology and water quality monitoring data from April to October in 2007 is shown as Fig. 4. The calibrate attenuation coefficient is similar to the value offered by the Songliao Water Conservation Commission. All the calculated relative error of water quality variable density are lower than $20 \%$, except the COD relative error of water quality variable density are closed to $30 \%$ at exception moment. This indicated that the model could meet the need of water quality simulation.
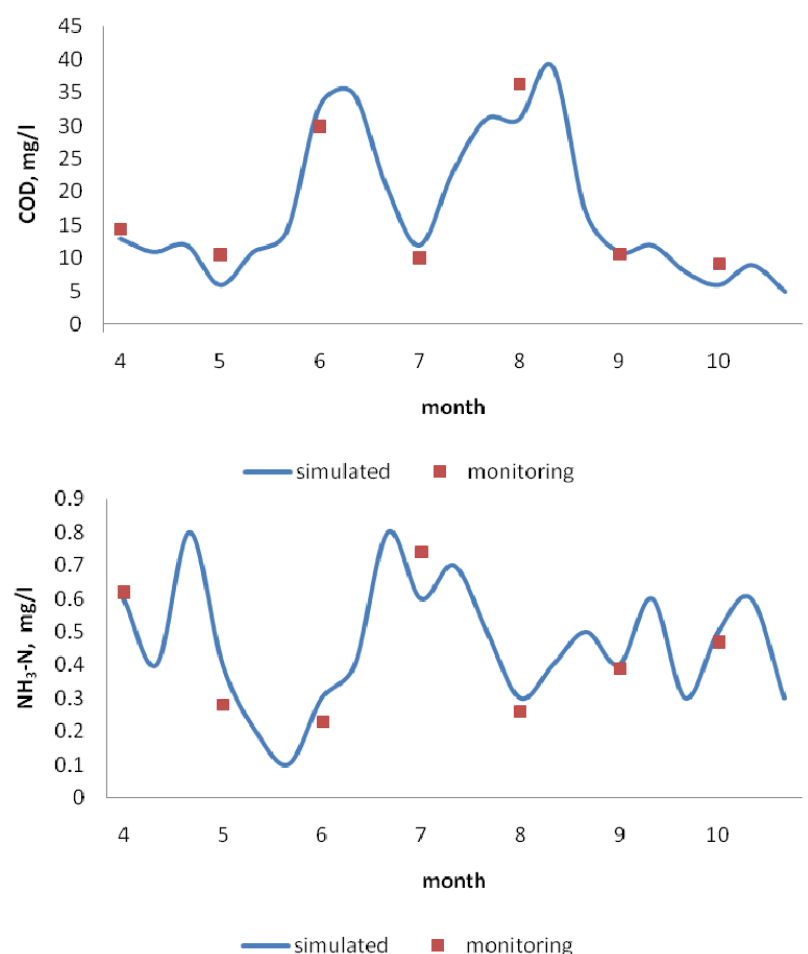

Fig. 4. Comparison of constituent concentration at WUJIA water quality monitoring station

\section{IMPACT ANALYSIS ON WATER QUALITY OF THE SECOND SONGHUA RIVER BASED ON MATHEMATICAL MODEL}

On the basis of the above study, to study the Impact analysis of upriver and tributaries on water quality of the second Songhua river main stream further, two schemes of simulating are presented: a) assumed that the water quality of tributary is improved from poor V to III of surface water quality standard in the same period, while the water quality of mainstream upstream inflow does not change; Secondly, the pollution load of upstream boundary water is reduced by $10 \%$ and its quality of tributaries water does not change. Under the
Conditions of assumptions, changes of the water quality of Wujia station are shown as follows:
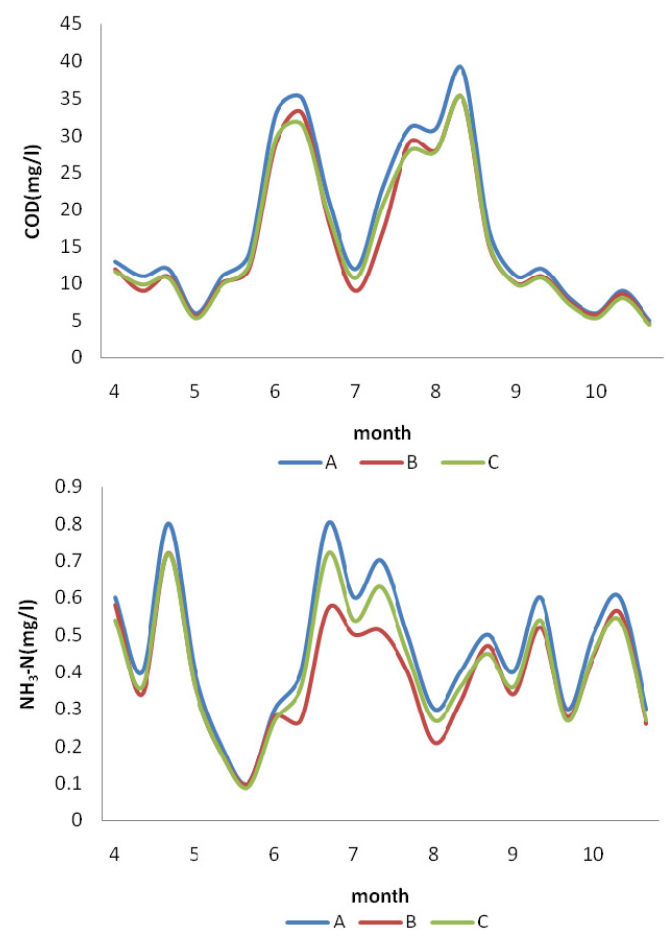

Fig. 5. Major pollution index concentration at WUJIA station under various conditions

A curve represents the background value (initial value); B curve represents changes in water quality when the tributary water quality reach the standardIII; C curve represents changes in water quality when the upper boundary water quality is improved.

From B curve in Fig. 5 We know that the water quality of downstream improved obviously from Jun to Aug, In the case of the Yinma III level during April to October, the index of $\mathrm{NH}_{3}-\mathrm{N}$ improved better than $\mathrm{COD}$, the maximum rate value of concentration changes will be up to $20 \%$, and there is no significant improvement in other months.

After the analysis of data, the main reasons are: 1) Ammonia nitrogen pollution is serious than COD pollution in the tributaries. 2) As shows in Fig. 6, the ratio of daily average discharges of Dehui to daily average discharges of Songhua river station is bigger during Jun to Aug in 2007 , even to $30 \%$. And at this time, the improvements of tributaries water quality have great influence of the main river. Most of the time, the rate is only below 5\%, that means the pollution from Yinma river flows in the main river will be diluted 200 times, so the density of the pollution from Yinma river will be greatly reduced.

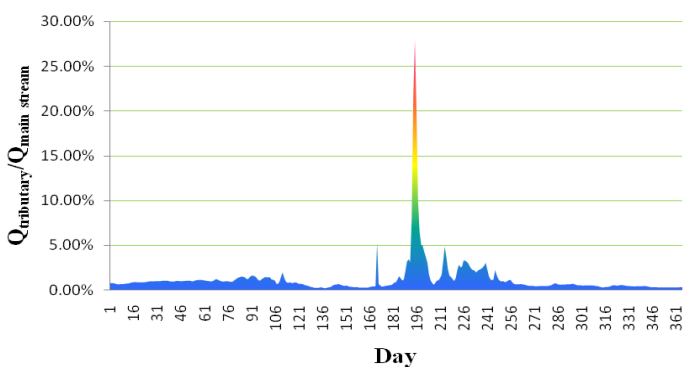

Fig. 6. The ratio of daily average discharges of Dehui to daily average discharges of Songhua river station in 2007 
Wujia water quality station has a certain degree of improvement according to water simulation results under conditions of two assumptions, in Fig. 5, while which can improve the quality more than major, also need to compare the pollution load reduction ratio of the tributary and upper boundary.

Curve $\mathrm{B}$ and $\mathrm{C}$ represent water quality changes, which seem approaching. But from the Table III, $\mathrm{NH}_{3}-\mathrm{N}$ pollution load of tributary need to cut down more than $90 \%$, CODcr pollution load need to reduce more than $40 \%$, when
tributary(Yinma river )meets Class III of National Surface Water Quality Standard, and river upstream pollution load only reduced by $10 \%$. According to the Changes in water quality of Wujia monitoring station in the downstream of the second Songhua river under the two scenarios and the pollution load reduction ratio of the tributary and upper boundary, the proportion of the upper boundary conditions have an absolute advantage in water quality improvement of main stream.

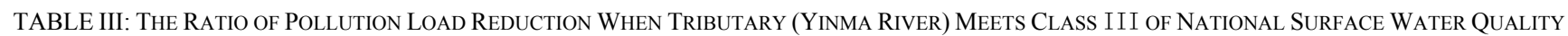
STANDARD

\begin{tabular}{|l|l|l|l|l|l|l|l|}
\hline Pollution Index & Apr & May & Jun & Jul & Aug & Sep & Oct \\
\hline $\mathrm{NH}_{3}-\mathrm{N}$ & $94.67 \%$ & $94.36 \%$ & $93.84 \%$ & $94.49 \%$ & $94.85 \%$ & $95.02 \%$ & $88.83 \%$ \\
\hline $\mathrm{CODcr}$ & $49.84 \%$ & $56.33 \%$ & $39.49 \%$ & $42.10 \%$ & $45.05 \%$ & $41.94 \%$ & $37.11 \%$ \\
\hline
\end{tabular}

\section{CONCLUSION}

A set of hydrodynamics and water quality model of the second Songhua River is developed. Based on it, the water quality in Yinma River meeting Class III of National Surface Water Quality Standard is predicted. The results indicated: if the tributaries meet Class III of National Surface Water Quality Standard, the water quality of Songhua River improving is bigger from Jun through Aug., ammonia nitrogen index is significantly improved.

Generally speaking, the ratio of daily average discharges of Dehui to daily average discharges of Songhua River (VI) station is only below 5\%, which means the pollution from Yinma river flows in the main river will be diluted 200 times. So the density of the pollution will be greatly reduced which can cause Yinma river water quality doesn't have an obvious effect on the main stream water quality most of the time.

The analysis shows that ammonia nitrogen index of main stream is influenced obviously by Yinma River in high flow period. Through evaluate the influence of Yinma river, analogize other tributaries (flow smaller and water quality better than Yinma river), which is less influence on the water quality of main stream.

According to the Changes in water quality of Wujia monitoring station in the downstream of the second Songhua River under the two scenarios and the pollution load reduction ratio of the tributary and upper boundary, the proportion of the upper boundary conditions have an absolute advantage in water quality improvement of main stream.

\section{REFERENCES}

[1] Songhua River Basin Water Pollution Control Program, (2006-2010). The Ministry of environmental protection of the people's Republic of China, Beijing, 2006.

[2] Q. C. Wang, Z. G. Shao, and L. Zhang, "Study on self-purification of the second Songhua River polluted by mercury in past 20 years," Acta Scientiae Circumstantiae., vol. 27, no. 3, pp. 474-479, 2007.

[3] W. Su, J. S. Liu, and F. Li, "Assessment on health risk of heavy metals in the second Songhua River," Journal of Agro-Environment Science, vol. 25, no. 6, pp. 1611- 1615, 2006.

[4] J. S. Liu and J. B. Yu, "Nitrogen content dynamic variation analysis in the second Songhua River," Chinese Journal of Environmental Science, vol. 18, no. 1, pp. 14-16, 1997.
[5] Z. X. Xu and H. L. Yin, "Development of coupled one-dimensional and two-dimensional hydrodynamic model for tidal rivers," Journal of Hydrodynamics, vol. 19, no. 6, pp.744-751, 2004.

[6] N. X. Zhao and P. Wang, "Program design for environmental fugacity model of toxical organic chemicals in Songhua river," Journal of Harbin Institute of Technology, vol. 33, no. 4, pp.479-481, 2001.

[7] J. Yu, G. Xu and J. X. Kang, "Application of a 1-D water quality forecast model in the calculation of contribution value," Environmental Science \& Technology, vol. 8, no. 29, pp.32-34, 2006.

[8] C. Wang, P. F. Wang, "Model of calculation water quantity needed to dilute and purify pollutants in river networks and its application," Journal of Hydrodynamics, vol. B-17, no. 4, pp. 418-428, 2005.

[9] J. M. Zhan, M. Y. Lu, and Y. X. Li, "An efficient accurate and applicable numerical model for unsteady flows in river networks," Journal of Hydrodynamics, vol. A-21, no. 6, pp. 685-692, 2006.

[10] F. Yuan and L. L. Ren, "A river routing model based on digital drainage networks," Journal of Hydrodynamics, vol. B-17, no. 4, pp. 483-488, 2005.

[11] J. B. Mu, X. F. Zhang, "Real-time flood forecasting method with 1-D unsteady flow model," Journal of Hydrodynamics, vol. B-19, no. 2, pp. 150-154, 2007.

[12] X. M. Xu, J. J. He, and D. J. Wang, "Nonlinear method on large scale river networks unsteady flow," Journal of Hydrodynamics, vol. A-16, no. 1 , pp. 18-24, 2001.

[13] D. J. Mossman and N. A. Mulki, "One-dimensional unsteady flow and unsteady pesticide transport in a reservoir," Ecological Modeling, vol. 89, pp. 259-267, 1996.

[14] D. A. Vieira, Modeling hydrodynamics, channel morphology and water quality using CCHE1D, 1st ed.Oxford, Mississippi, USA, 2006, pp. 1-13.

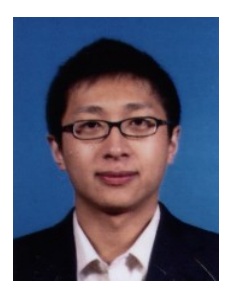

Shaochen Sun was born in Neng Jing, Hei Longjiang Province in July 19, 1982. From Sep 2000 to Jun 2004, He studied in the Northeast Forestry University (Harbin, China), majoring in environmental science and got his bachelor degree in 2004. He then moved to University of South (Hengyang City, China), majoring in HVAC engineering, and received his master degree in 2007. He will graduate from Donghua University (Shanghai City, China) in October 2013 with $\mathrm{PhD}$ degree of Environmental Science and Engineering. His research interests focus on the simulation of water environment and the study on pollution control technology. Papers published in recent three years are as follows: 1) Sun Shao-chen, "Application of the Freezing Period Hydrodynamics and Water Quality Model to Water Pollution Accident in Songhua River," Journal of Jilin University(Earth Science Edition)., vol. 41, no. 5,pp. 1548 1553, 2011. , 2) Sun Shaochen, Xiao Weihua, Zhou Zuhao Wang Hao, "The Study and Application of Hydrodynamic Numerical Simulation Method in Cold Region," 2010 Conference on Moden Hydraulic Engineering, pp. 182-186, 2010. 